Title:

\title{
Integrating Chemistry into 3D Climate Models: Detailed Kinetics in the Troposphere and Stratosphere of a Global Climate Model
}

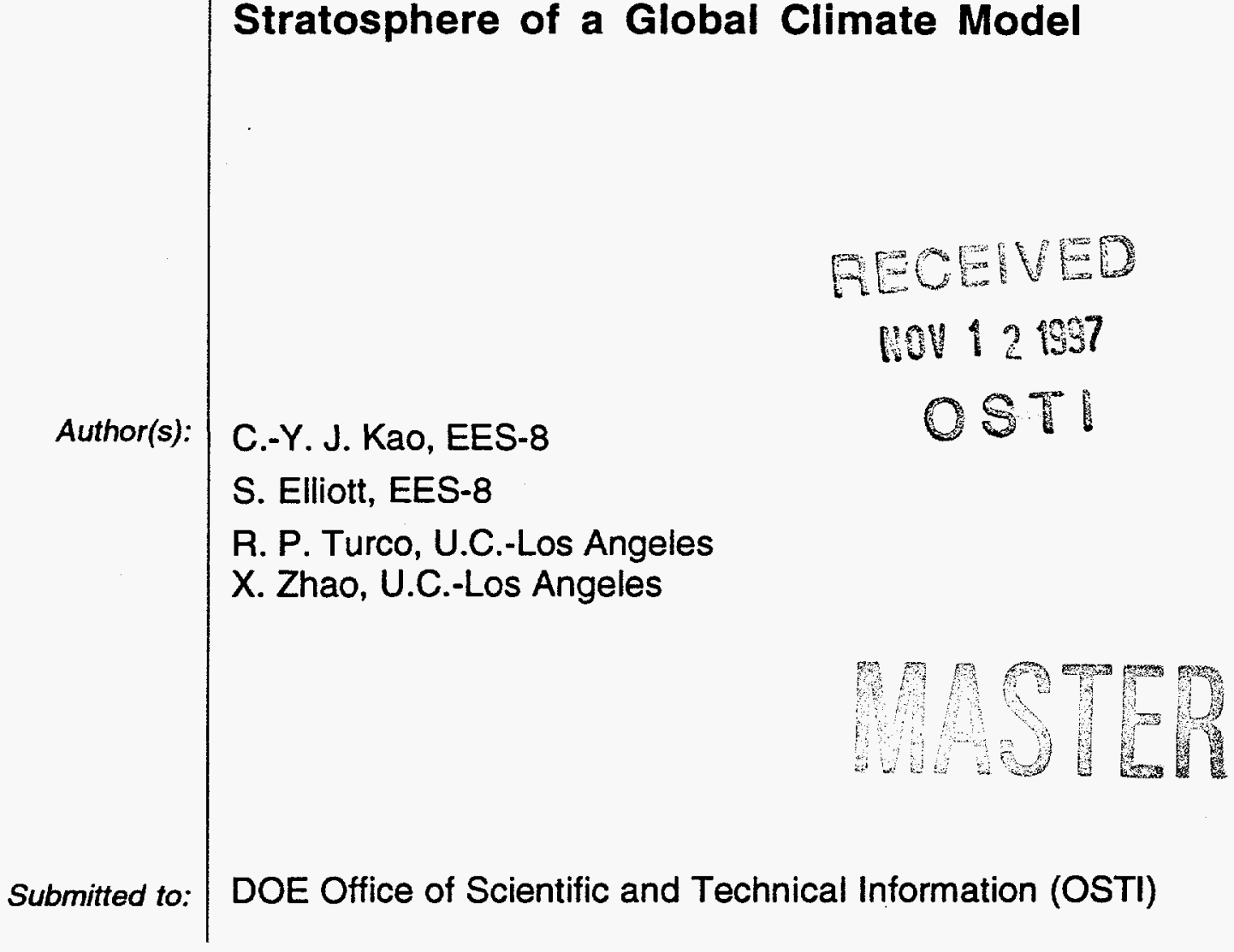

DISCLAIMER

This report was prepared as an account of work sponsored by an agency of the United States Government. Neither the United States Government nor any agency thereof, nor any of their employees, makes any warranty, express or implied, or assumes any legal liability or responsibility for the accuracy, completeness, or usefulness of any information, apparatus, product, or process disclosed, or represents that its use would not infringe privately owned rights. Reference herein to any specific commercial product, process, or service by trade name, trademark, manufacturer, or otherwise does not necessarily constitute or imply its endorsement, recommendation, or favoring by the United States Government or any agency thereof. The views and opinions of authors expressed herein do not necessarily state or reflect those of the United States Government or any agency thereof.

\section{Los Alamos}

NATIONAL LABORATORY
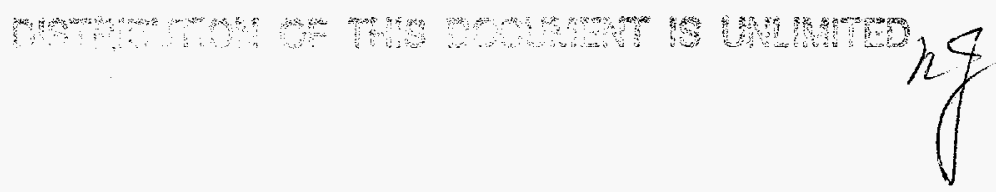

Los Alamos National Laboratory, an affirmative action/equal opportunity employer, is operated by the University of California for the U.S. Department of Energy under contract W-7405-ENG-36. By acceptance of this article, the publistrer recognizes that the U.S. Govemment retains a nonexclusive, royaltyfree license to publish or reproduce the published torm of this contribution, or to aliow others to do so, for U.S. Government purposes. Los Alamos National Laboratory requests that the publisher identity this article as work performed under the auspices of the U.S. Department of Energy. Los Alamos National Laboratory strongly supports academic freedom and a researcher's right to publish; as an institution, however, the Laboratory does not endorse the vieupoint of a publication or guarantee its technical correctness. 


\section{DISCLAMIER}

Portions of this document may be illegible in electronic image products. Images are produced from the best available original document. 


\title{
Integrating Chemistry into 3D Climate Models: Detailed Kinetics in the Troposphere and Stratosphere of a Global Climate Model
}

\author{
Chih-Yue Jim Kao and Scott Elliott \\ Earth and Environmental Sciences Division \\ Los Alamos National Laboratory \\ Richard P. Turco and Xuepeng Zhao \\ University of California at Los Angeles
}

\begin{abstract}
This is the final report of a three-year, Laboratory Directed Research and Development (LDRD) project at Los Alamos National Laboratory (LANL). The motivation for the project is to create the first complete, threedimensional climate model that enfolds atmospheric photochemistry. The LANL chemical global climate model (GCM) not only distributes the trace greenhouse gases and modifies their concentrations within the detailed photochemical web, but also permits them to influence the radiation field and so force their own transport. Both atmospheric chemistry and fluid dynamics are nonlinear and zonally asymmetric phenomena. They can only be adequately modeled in three dimensions on the global grid. Our kineticsaugmented GCM is the only program within the atmospheric community capable of investigating interaction involving chemistry and transport. We have conducted case studies of timely three-dimensional chemistry issues. Examples include ozone production from biomass burning plumes, kinetic feedbacks in zonally asymmetric transport phenomena with month- to yearlong time scales, and volcano sulfate aerosols with respect to their potential effects on tropospheric ozone depletion.
\end{abstract}

\section{Background and Research Objectives}

Historically within the atmospheric sciences community a segregation has existed between studies of chemistry and dynamics. This division has persisted even into the era of global climate change. A third of the greenhouse effect will likely be attributable to trace species with distributions controlled by an intimate interplay of photochemical production and loss with transport, the primary examples being ozone and methane (IPCC, 1992). Yet the chemical kinetics underlying climate have almost invariably been simulated interactively only in contexts of two dimensions or less in which atmospheric motions must

\footnotetext{
- Principal Investigator, E-mail: kao@vega.lanl.gov
} 
be parameterized to a high degree (Ramanathan et al., 1987). The few chemical calculations actually performed on three-dimensional global climate model (GCM)-style grids have almost invariably occurred off line (noninteractively), so that greenhouse alterations could not feed back through physics routines into dynamics. A subsidiary segregation has been apparent within the transport regime. Atmospheric kinetics computations often deal with regions above and below the tropopause separately.

Our research project was to bridge both these gaps simultaneously by inserting detailed photochemistry into the troposphere and stratosphere of a GCM. From a computational standpoint, the project has been challenging. Full kinetic modeling of the stratosphere requires integration of more than 50 individual species reacting through over 150 photochemical channels. The stratospheric system is highly stiff, meaning that time constants for the constituents vary widely. Tropospheric chemistry is several times more complex, and the hundreds of disparate atmospheric chemical tracers and reactions must be condensed onto massive grids containing a hundred thousand or more cells. The conjunction of large numbers of chemical species and grid cells with stiffness has long kept chemistry-climate interaction at the frontiers of computational feasibility. Even the most experienced atmospheric science groups have to date been unwilling to tackle the problem. Los Alamos National Laboratory (LANL), however, has been in a unique position to succeed in construction of a chemical GCM. The Earth and Environmental Sciences (EES) Division at Los Alamos has been laying the necessary groundwork for several years. Advances that EES researchers have made now place the chemical coupling well within the reach of the atmospheric sciences.

EES researchers had run extensive tests of the Los Alamos general circulation model in anticipation of incorporating detailed kinetics. An off line chemical tracer model (CTM) attachment was developed to compare calculated and observed distributions of several greenhouse species, thus validating wind fields for dispersion of trace gases (Kao et al., 1992). More importantly, EES was the only atmospheric group in the world with real experience simulating three-dimensional (3-D) interactions of chemistry and climate. First, Kao et al. (1990) incorporated a key subset of the complete inorganic chemical scheme into the stratosphere of the GCM. In the past ten years, we have collaborated with researchers at the University of California campuses to build sophisticated kinetics packages fast enough to reproduce the entire photochemical set across hundreds of thousands of cells (Elliott et al., $1993 \mathrm{a}$ and b). Preliminary but fully interactive tests within the LANL GCM stratosphere indicated that detailed photochemical-climate calculations were feasible even on older vector machines (Elliott et al., 1993b). The 
kinetics are also flexible in terms of their reactions schemes, parallelized for a smooth transition to the new generation of parallel processing supercomputers, and modular so that they are compatible with other transport frameworks. Our chemical packages have ultimately been designed to function within earth system models blending physics with the major biogeochemical cycles.

\section{Importance to LANL's Science and Technology Base and National R\&D Needs}

Among the missions of the DOE is consideration of a national energy strategy. Energy usage drives climate change in all senses, and the kinetically active greenhouse gases are no exception. Tropospheric ozone production is controlled by oxidation of hydrocarbons released during fossil fuel combustion. Stratospheric ozone loss stems from $\mathrm{CFC}$ releases, which track industrial output. Methane increases are associated with population growth, which is energy limited. Climate research at LANL contributes to the shaping of an energy strategy. Our pioneering chemistry interactive GCM will not only compliment DOE and Laboratory efforts in energy management, but may well propel us to the cutting edge of a new and exciting field. Emphases will encompass tropospheric increases and stratospheric depletion as well as modeling to understand them. Comprehension can only come through interactive photochemical and climate simulations. Our work has provided Los Alamos and the DOE with a sophisticated basis for analysis of all global ozone problems. Concern for the environment is another essential element of competitiveness in the coming world economy, and the impact of manufacturing on the terrestrial system can only be assessed through global modeling efforts.

At least three projects at LANL will benefit from cross fertilization with our work:

- Our kinetics packages have already demonstrated extreme efficiency on the global grid and, given proper interfacing, will run swiftly on the regional scale as well. LANL operates both the RAMS and HOTMAC mesoscale models. Support for their maintenance has come through DOE ASCOT and ARM funding.

- The LANL CHAMMP project studies the conversion of complex geophysical models to massively parallel processors. Since chemistry can be independent of neighboring cells, and our program architecture accounts for parallelism by maximizing vector lengths, the kinetics are already adapted for parallel GCMs. 
- Our chemical computations can well compliment measurements resulting from the LIDAR technique, which proves efficient for studying atmospheric constituent fields.

\section{Scientific Approach and Accomplishments}

The foundation for the photochemical experiments has been the LANL GCM (Kao et al., 1990). The program is spectral with an equivalent Eulerian grid of 4.5 degrees latitude by 4.5 degrees longitude. Vertical resolution has been enhanced to a total of twenty levels-twelve tropospheric and eight stratospheric. Radiative forcing includes long- and short-wave ozone bands. We began formulation of the complete 3-D chemistry climate program with a series of tropospheric kinetics experiments in the off line Chemical Tracer Model (CTM). Experimentations with hydrocarbon configurations have reduced uncertainties in organic reaction schemes (Elliott et al., 1996). In the troposphere, we have focused on ozone precursors - the hydrocarbons, and nitrogen and hydrogen oxides. In the stratosphere, chlorine/ozone chemistry has been investigated within disturbed wave structures. As parallelized climate models find their way onto multiple processing machines, our chemistry can readily be integrated, since it was designed precisely to make this transition. Parallel calculation approaches will someday allow modeling of the entire biogeochemical/climate system, and our modular photochemistry packages can play a vital role.

The major problems in the 3-D global photochemistry modeling in terms of computational speed, numerical instability, and chemical species mass conservation have been remedied using our improved numerics and automation with a novel chemical parameterization. A 60-species stratospheric dataset has been inserted into the LANL GCM, and coupled chemical-dynamical simulations have reached one annual cycle in length. The results show that the diurnal behaviors of short lived species are well captured even though a relatively large time step is used in the integration. The global features of ozone variation are in agreement with satellite measurements; however, with $10 \%$ overestimation by the model simulations. This discrepancy may well be due to the anthropogenical effects. In the tropospheric regime, we have been utilizing automated continuity equations within the kinetics codes to experiment with organic oxidation chains affecting ozone and methane distributions. An integrator with complete hydrocarbon kinetics developed at Turco's group at UCLA has been tested. We have also adopted NCAR CCM2 as another testbed for our photochemistry development. The NCAR CCM2 
is a user-friendly, plug-compatible, and well-coded GCM that has been used at LANL since 1993. We have recently conducted a 40-year simulation (Kao et al. 1996) with realistic sea-surface temperatures observed from 1950-1989 as lower boundary conditions to drive the NCAR CCM2. The semi-Lagrangian technique for advecting positive-definite species mixing ratios is used for our chemical experiments in CCM2.

We have conducted case studies in the tropospheric CTM of timely3-D chemistry issues. Examples include simulation of ozone production from biomass burning plumes (Kao et al., 1994) and subsonic aircraft emissions. In the coupled chemical GCM stratosphere we have investigated kinetic feedbacks in zonally asymmetric transport phenomena with month- to year-long time scales. Examples include breaking waves (Kao et al., 1995), rapid poleward transport and heterogeneous chemistry. Volcano sulfate aerosols have been studied with respect to their potential effects on tropospheric ozone depletion (Zhao et al., 1996). We have incorporated the final tropospheric kinetics package into CCM2 and examined the tropospheric problems interactively. Comparisons with our chemical GCM results have calibrated lower dimensionality calculations (Zhao et al., 1996, submitted). 


\section{Publications}

Elliott, S., M. Shen, C.-Y. J. Kao, R. P. Turco, and M. Jacobson, A streamlined family photochemistry module reproduces major nonlinearities in the global tropospheric ozone system. Comput. Chem., 20, 235-259, 1996.

Elliott, S., R. P. Turco, X. Zhao, C.-Y. J. Kao, and M. Shen, Photochemical numerics for global scale modeling: Fidelity and GCM testing. J. Appl. Meteo., 34, 694-718, 1995.

Kao, C.-Y. J., S. Barr, A. Quintanar, D. Langley, G. A. Glatzmaier, and R. C. Malone, Numerical modeling of tracer transport within and out of the lower tropospheric Arctic region. Geophys. Res. Lett., 22, 941-944, 1994.

Kao, C.-Y. J., G. A. Glatzmaier, and R. B. Malone, On testing the statistical significance of climate response simulated by general circulation model to smoke from Kuwaiti oil fires with improved hydrological physics. J. Geophys. Res., 99, 14503-14508, 1994.

Kao, C.-Y. J., A. Quintanar, M. J. Newman, D. Langley, and S.-C. Chen, Climate simulations with NCAR CCM2 forced by global sea surface temperatures in 1950-1989. (November Issue), 1996.

Zhao, X, and R. P. Turco, 1996: Parameterization of photodissociation rates for 3-D modeling. J. Geophys. Res., (Submitted).

Zhao, X., R. P. Turco, C.-Y. J. Kao, and S. Elliott, Numerical simulations of dynamical response to the Arctic vortex to aerosol-associated chemical perturbations in the lower stratosphere, Geophys. Res., Lett., 12, 1525-1528, 1996.

Zhao, X., R. P. Turco, C.-Y. J. Kao, and S. Elliott, Aerosol induced chemical perturbations of stratospheric ozone: Three-dimensional simulations and analysis of mechanisms. J. Geophys. Res., (Submitted) 


\section{References}

Cicerone, R. J., S. Elliott, and R. P. Turco, Reduced Antarctic ozone depletions in a model with hydrocarbon injections, Science 254, 1191-1194, 1991.

DOE/OHER, Overview of the DOE atmospheric chemistry program's ozone project, DOE /ER-0575T, Office of Scientific and Technical Information, Oak Ridge TN, 1993.

Elliott, S., R. P. Turco, and M. Z. Jacobson, Tests on combined projection/forward differencing integration for stiff photochemical family systems, Computers and Chemistry 17(1), 91-102, 1993a.

Elliott, S., R. P. Turco, X. P. Zhao, M. Shen, and C. Y. J. Kao, Efficient and modular kinetics packages for global scale photochemical modelling. In The Role of Meteorology in Managing the Environment of the Nineties, edited by A. Roffman, Air and Waste Management Association, Pittsburgh, 1993b.

IPCC (the Intergovernmental Panel on Climate Change), Update of 1990 Report, chapter on Greenhouse Gases, Cambridge University Press, 1992.

Kao, C. Y. J., G. A. Glatzmaier, R. C. Malone, and R. P. Turco, Global three dimensional simulations of ozone depletion under postwar conditions, J. Geophys. Res. 95, 22495-22512, 1990.

Kao, C. Y. J., X. Tie, E. Mroz, D. Cunnold, and F. Alyea, Simulations of global CFC-11 using the Los Alamos chemical tracer model, J. Geophys. Res. 97, 15827-15838, 1992.

Ramanathan, V., L. Callis, R. Cess, J. Hansen, I. Isaksen, W. Kuhn, A. Lacis, F. Luther, J. Mahlman, R. Reck, and M. Schlesinger, Climate-chemical interactions and effects of changing atmospheric trace gases, Rev. Geophys. 25(7), 1441-1482, 1987.

Tie, X., C. Y. J. Kao, E. Mroz, R. J. Cicerone, F. N. Alyea, and D. M. Cunnold, Three dimensional simulations of atmospheric methyl chloroform: effect of an ocean sink, J. Geophys. Res. 97, 20751-20769, 1992.

Turco, R. P., O. B. Toon, T. P. Ackerman, J. B. Pollack, and C. Sagan, Nuclear Winter: global consequences of multiple nuclear explosions, Science 222, 1293-1298, 1983. 